\section{High-Magnification Chromoscopic Ileoscopy in Familial Adenomatous Polyposis: Detection In Vivo of Colonic Metaplasia and Microadenoma Formation}
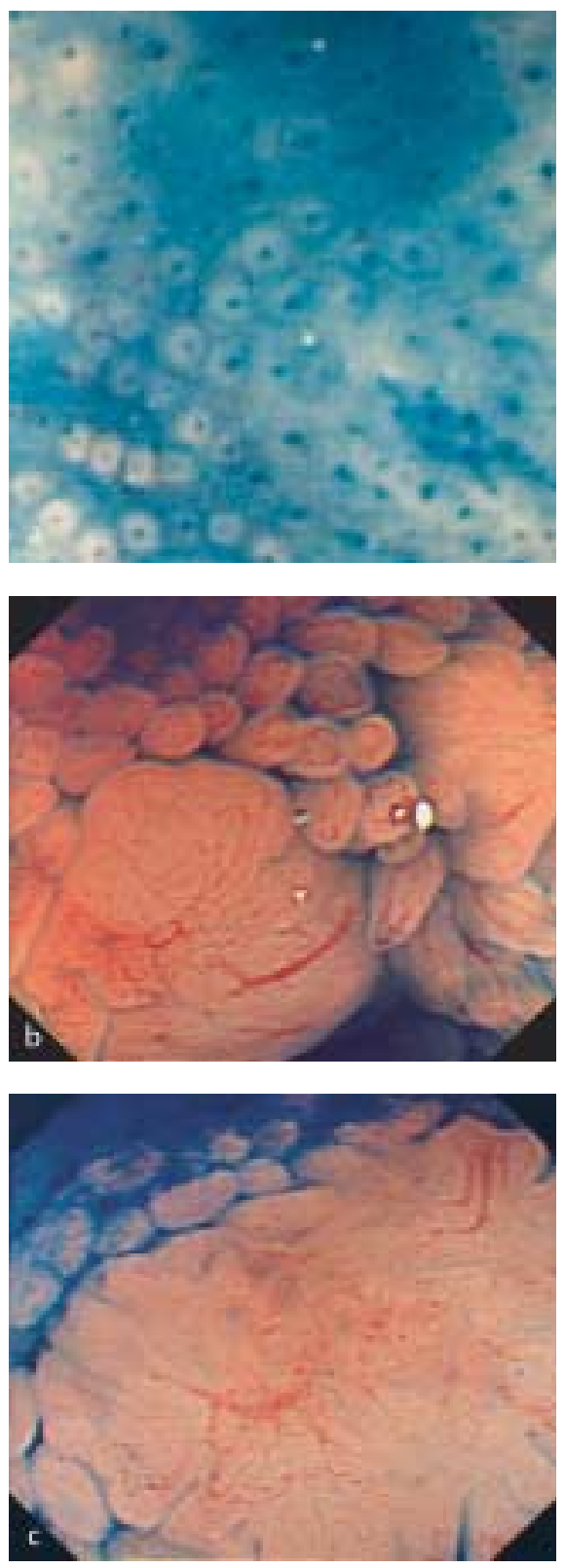

Figure 1 lleal microadenomas with morphological features similar to colorectal aberrant crypt foci occur in the ileum of patients with familial adenomatous polyposis (FAP). Ileal microadenomas may occur secondarily to ileal-coIonic metaplasia. High-magnification chromoscopic endoscopy permits in vivo observation of this phenomenon. These views were obtained during a 50-cm ileoscopy of a patient with sporadic FAP. a Terminal-ileal views at $5 \mathrm{~cm}$ from the ileocaecal valve using $0.05 \%$ indigo carmine. The villous pattern is replaced with a Kudo type I crypt typical of columnar epithelium (magnification $\times 100$ ). b and $\mathbf{c}$ View at $10 \mathrm{~cm}$ from the ileocaecal valve using $0.05 \%$ indigo carmine. Diminutive protrusions cluster among the normal "round" villous network. The protruded areas demonstrate small crypt openings (magnification $\times 100$ ).

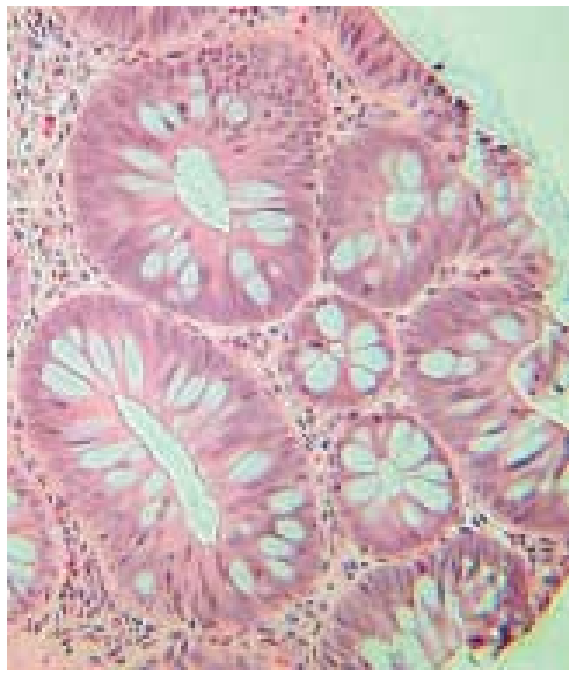

Figure 2 Microadenoma of Figure $\mathbf{1} \mathrm{c}$ at histopathological examination (haematoxylin \& eosin stain).

D. P. Hurlstone' ${ }^{1}$, S. S. Cross ${ }^{2}$, A. J. Lobo'

${ }^{1}$ Department of Gastroenterology, Royal Hallamshire Hospital, Sheffield, UK

${ }^{2}$ Academic Unit of Pathology, Section of Oncology and Pathology, Division of Genomic Medicine, University of Sheffield Medical School, Sheffield, UK

Corresponding Author

D. P. Hurlstone, M. B. Ch.B.

Room P14/Ward P2

Royal Hallamshire Hospital

Sheffield S10

United Kingdom

Fax: $\quad$ +44-114-2712692

E-mail: dphurlstone@doctors.org.uk 